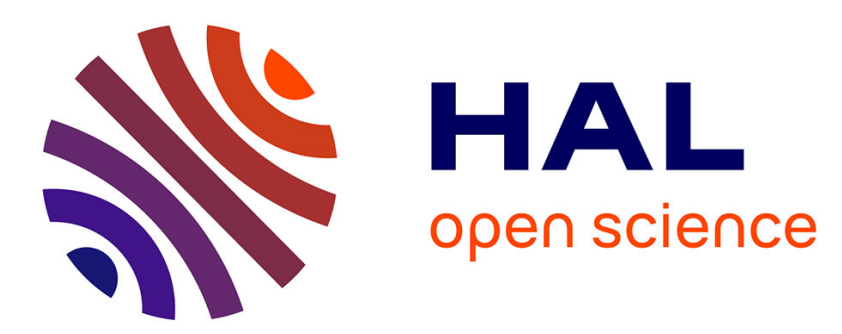

\title{
The effects of perceived competence and sociability on electoral outcomes
}

Luigi Castelli, Luciana Carraro, Claudia Ghitti, Massimiliano Pastore

\section{To cite this version:}

Luigi Castelli, Luciana Carraro, Claudia Ghitti, Massimiliano Pastore. The effects of perceived competence and sociability on electoral outcomes. Journal of Experimental Social Psychology, 2009, 45 (5), pp.1152. 10.1016/j.jesp.2009.06.018 . hal-00711866

\section{HAL Id: hal-00711866 https://hal.science/hal-00711866}

Submitted on 26 Jun 2012

HAL is a multi-disciplinary open access archive for the deposit and dissemination of scientific research documents, whether they are published or not. The documents may come from teaching and research institutions in France or abroad, or from public or private research centers.
L'archive ouverte pluridisciplinaire HAL, est destinée au dépôt et à la diffusion de documents scientifiques de niveau recherche, publiés ou non, émanant des établissements d'enseignement et de recherche français ou étrangers, des laboratoires publics ou privés. 


\section{Accepted Manuscript}

The effects of perceived competence and sociability on electoral outcomes

Luigi Castelli, Luciana Carraro, Claudia Ghitti, Massimiliano Pastore

PII:

S0022-1031(09)00145-0

DOI:

10.1016/j.jesp.2009.06.018

Reference:

YJESP 2302

To appear in:

Journal of Experimental Social Psychology

Received Date:

15 December 2008

Revised Date:

7 May 2009

Please cite this article as: Castelli, L., Carraro, L., Ghitti, C., Pastore, M., The effects of perceived competence and sociability on electoral outcomes, Journal of Experimental Social Psychology (2009), doi: 10.1016/j.jesp. 2009.06.018

This is a PDF file of an unedited manuscript that has been accepted for publication. As a service to our customers we are providing this early version of the manuscript. The manuscript will undergo copyediting, typesetting, and review of the resulting proof before it is published in its final form. Please note that during the production process errors may be discovered which could affect the content, and all legal disclaimers that apply to the journal pertain. 
Running head: Predicting the vote

\title{
The effects of perceived competence and sociability on electoral outcomes
}

\author{
Luigi Castelli, Luciana Carraro, Claudia Ghitti, \& Massimiliano Pastore
}

University of Padova, Italy

Corresponding author:

Luigi Castelli

DPSS - via Venezia, 8, 35131 Padova - Italy

Email: castelli.luigi@unipd.it

Keywords: Competence, Facial Features, Voting Behavior, Political Elections

Abstract

Previous research demonstrated that inferences of competence from the face are good predictors of electoral outcomes (Todorov et al., 2005). In the current work we examined the role of another key dimension in social perception, namely perceived sociability. Results showed that people considered both competence and sociability, as inferred from the face, as related to higher chances of winning the elections. A different pattern emerged in relation to the actual electoral outcomes.

Indeed, perceived competence was related to higher chances of winning, whereas perceived sociability was negatively related to electoral success. It is thus shown that these two fundamental dimensions in social perception exert opposite effects on voting behaviors. 
Running head: Predicting the vote

The effects of perceived competence and sociability on electoral

outcomes 


\begin{abstract}
Previous research demonstrated that inferences of competence from the face are good predictors of electoral outcomes (Todorov et al., 2005). In the current work we examined the role of another key dimension in social perception, namely perceived sociability. Results showed that people considered both competence and sociability, as inferred from the face, as related to higher chances of winning the elections. A different pattern emerged in relation to the actual electoral outcomes. Indeed, perceived competence was related to higher chances of winning, whereas perceived sociability was negatively related to electoral success. It is thus shown that these two fundamental dimensions in social perception exert opposite effects on voting behaviors.
\end{abstract}


The effects of perceived competence and sociability on electoral outcomes.

Extensive research during the last decades has identified two core dimensions underlying person and group perception: warmth and competence (Fiske, Cuddy, Glick, \& Xu, 2002; for reviews see Cuddy, Fiske, \& Glick, 2008; Fiske, Cuddy, \& Glick, 2007). Warmth basically refers to the aptitude to carry out harmonious social relations and signals that the perceived target can be profitably approached. In contrast, competence is related to the possession of skills and capabilities that enable to achieve one's own goals. In sum, warmth captures the relational aspects of social life whereas competence underlines task-oriented behaviors. Importantly, the relevance of these two dimensions emerged also in studies about politics. Indeed, in the evaluation of political candidates two major dimensions are usually reported, namely warmth and competence (e.g., Funk, 1996), with the possible addition of moral integrity (Kinder \& Sears, 1985). Moreover, competence appears to be the strongest determinant of voting behaviors, especially in the case of people with high political expertise (Funk, 1997).

Even though some authors proposed slightly different frameworks and labels (Rosenberg, Nelson, \& Vivekananthan, 1968; Wojciszke, Bazinska, \& Jaworski, 1998), there is consistent evidence that these two dimensions account for most of the variance in the evaluation of social targets. Most importantly, the placement of a person or a group along the warmth and competence dimension shapes the emotional reactions and directs the behaviors toward such target (Cuddy, Fiske \& Glick, 2008). Information about competence and warmth can be derived in several ways, like the direct observation of behaviors or secondhand reports. The face is also a primary source for inferring personality features (Todorov, Said, Engell, \& Oosterhof, 2008; Zebrowitz \& Montepare, 2008). Todorov and colleagues have shown that even after very brief exposures to a face perceivers can effectively extract inferences (Willis \& Todorov, 2006), and that such inferences about the competence of gubernatorial candidates are good predictors of election outcomes (Todorov, 
Mandisodza, Goren, \& Hall, 2005). More specifically, Todorov and colleagues (2005) showed participants the faces of two unknown competing candidates who were running against each other and asked them to evaluate their competence from their physiognomic traits. Candidates who were perceived as more competent were actually more likely to win the election, and judgments of competence were also significantly related to the difference in votes between the two candidates. In addition, the authors demonstrated that the results could not be accounted in terms of halo effects, and that the effects remained significant even after controlling for other positive judgmental dimensions, such as pleasantness or honesty (Todorov et al., 2005).

While the effects of perceived competence on voting behavior seem well-established (Ballew \& Todorov 2007; Chiao, Bowman, \& Gill, 2008; Todorov et al., 2005; see also Rule \& Ambady, 2008), the role of perceived warmth, as inferred from the face, have not yet been investigated. On the one hand, it could be expected that perceived warmth increases the chances to win an electoral race given that high social skills could be seen as a tool to increase consensus and to smooth conflicts. On the other hand, however, high perceived sociability could be associated to excessive attention to interpersonal relations and to a consequent high malleability and low dominance. Interestingly, warmth and competence seem to be interconnected and changes on perceived warmth may impact on perceived competence. Indeed, Judd, Yzerbyt and their colleagues (Judd, JamesHawking, Yzerbyt, \& Kashima, 2005) suggested the existence of a negative dynamic relationship between the two. Experimental manipulations of the location of a target on one dimension affects the perceived location on the other, such that compensatory effects arise indicating that positive judgments on one dimension leads to more negative judgments on the other (Judd et al., 2005; Kervyn, Judd, Yzerbyt, in press; Kervyn, Yzerbyt, Demoulin, \& Judd, 2008; Kervyn, Yzerbyt, Judd, \& Nunes, 2009; Yzerbyt, Kervyn, \& Judd, 2008). As such, one possibility is that while perceived competence represents an additional arrow in the bow of a politician, a face signaling high sociability might turn out to be disadvantageous. 
In the following study, we will examine this issue drawing upon the procedure employed by Todorov and colleagues (2005). Faces of politicians involved in local elections were presented and judgments of competence, sociability, morality, and pleasantness were asked. We expected that positive evaluations on these dimensions would be all positively related to individual predictions about the likely winner. In contrast, in relation to the actual outcomes of the election, we expected perceived competence to be positive related, like in the aforementioned studies (e.g., Todorov et al., 2005), whereas perceived warmth was expected to be negatively related to the likelihood of winning the electoral competition. Morality was included as an additional factors because of its likely relevance for political judgments (Kinder \& Sears, 1985), and at the light of recent approaches that identify morality as a third key dimension in social perception (Leach, Ellemers, \& Barreto, 2007; but see Abele \& Wojciszke, 2007).

\section{The study}

Participants. Fifty-six persons (42 females) volunteered to fill in the questionnaire. Their age ranged between 20 and 35 years $(M=25.1, \mathrm{SD}=3.76)$.

Material. Twenty pairs of head-and-shoulder photographs of the winners and the runners-up were selected. The two politicians for each pair were competing against each other as majors in local elections in Italy. Elections took place in regions far away from the one where the data were collected so that to minimize the likelihood of previous exposure to the faces.

Procedure. The twenty pictures were randomly divided into two subsets of 10 pictures. Each participant was randomly required to evaluate only one set. The experimenter first displayed the pictures of the two competing candidates next to each other. Participants were instructed to look carefully at the two faces and for each of them to rate the following aspects: age, competence, morality, sociability, pleasantness, and regional prototypicality (e.g., how much the facial traits were typical of the North vs. South of Italy). Age was rated by writing the corresponding number, 
whereas responses on the other dimensions were provided along a 10 centimeters long continuum anchored from "very low" to "very high". Finally, participants were asked to guess which of the two candidates had won the election. The same sequence was followed for all ten pairs of pictures. Finally, participants were thanked and debriefed.

\section{Results}

First, for each participant we calculated differential scores between the judgments provided toward one specific candidate and those provided toward the opponent. Thus, for each participant and each couple of faces we had an indication of how much one candidate was perceived as more competent, sociable, moral, pleasant, prototypical of the North, and old as compared to the other candidate. A series of hierarchical linear models was then performed in order to assess the relationship between these difference scores and the predicted and actual electoral outcomes. Multilevel modeling allows to account for the dependency in observations when data have a nested structure enabling to remove the variance due to the material and the participants.

The subjective predictions about the likely winner. As said, participants were asked to guess which of the two candidates had won the election. The 20 pairs of candidates were included at level 1 of the hierarchical model. Second-level units were the 56 participants ${ }^{1}$. Results showed that three variables (i.e., morality, prototypicality, and age) were unrelated to subjective predictions. In contrast, the candidate who was perceived as more competent, sociable, and pleasant, as compared to the opponent, was also indicated as the more likely winner (see Table 1). In sum, according to participants' naïve theories, candidates whose faces are more pleasant and signal competence and sociability are expected to win.

The prediction of the actual winner. In this case, the hierarchical model only included the participants as first-level units ${ }^{2}$. Results showed quite a different picture as compared to the subjective predictions. Indeed, in this case only two predictors were significantly related to the 
actual electoral outcome, namely competence and sociability (see Table 1). More specifically, competence was positively related. Confirming previous research, (apparently) competent candidates were more likely to be elected. Conversely, the perception of sociability was negatively related to the likelihood of winning the race. The more a candidate was perceived as sociable, as compared to the other candidate, the lower the chances to be elected ${ }^{3}$.

In addition to the prediction of the actual winner, we examined whether inferences from the faces were related to the margin of the victory ${ }^{4}$. As before, the hierarchical model only included the participants as first-level units. Results showed that three variables predicted the margin of the victory: perceived competence, sociability, and age (see Table 1). Results showed that inferences of competence from the face were linearly and positively related to the difference in the percentage of votes between the two candidates. However, inferences of sociability were negatively related to the difference in the percentage of votes. Thus, perceived sociability was associated to higher chances to lose the election as well as to the margin of the defeat. Perceived age was also negatively related suggesting that candidates looking younger were more likely to triumph over their opponents.

\section{General Discussion}

The present results do provide further evidence about the power of perceived competence, as inferred from facial features, in shaping voting behaviors (Todorov et al., 2005). Indeed, candidates who were perceived as more competent were more likely to win the race, and the margin of the victory was also related to the gap in perceived competence. In addition to confirming previous results, it is here shown that an additional inferred dimension - perceived sociability - can have a negative impact on the likelihood of winning an election. Candidates who scored higher on perceived sociability had lower chances to win. As discussed in the introduction section, competence and sociability tend to be somehow negatively related and perceivers are inclined to attribute competence when sociability is low and viceversa (Judd et al., 2005; Kervyn et al., 2008; 
Yzerbyt et al., 2008). The dynamical relationship between these two dimensions seems to entail also their effects on relevant social judgments. It is here shown that while perceived competence fosters victorious political races, perceived sociability represents a disadvantageous factor. A successful candidate thus appears to require a facial aspect signaling competence but also low sociability. This finding, however, does not necessarily hold true in any political context. For instance, Little and colleagues (Little, Burriss, Jones, \& Roberts, 2007) have shown that the preference for candidates' specific facial features can change on the basis of the political environment, either prosperous and peaceful or depressed and violent. In the latter case, strong leaders are preferred whereas in the former case it could well be the case that more sociable leaders would be preferred.

Even though we had no a-priori hypothesis, we also explored the effects associated to perceived morality. Morality, as inferred from the face, played a role neither on subjective predictions nor on real outcomes. It is difficult to draw conclusions on this null finding which might indicate that morality is somehow subsumed by the sociability dimension (see Abele \& Wojciszke, 2007), or that the perception of morality is actually less relevant in the formation of voting intentions as compared to the other two dimensions (even though it is indeed a major source of influence in other social domains; see Leach et al., 2007). Of course, the current data only speak about the impact of facial appearance, and morality could well shape political decisions when conveyed through more articulated information like the description of specific behaviors performed by political candidates (Kinder \& Sears, 1985).

Another interesting finding comes from the comparison of real outcomes and individual forecasting. Indeed, competence and sociability have opposite effects on the prediction of actual voting behaviors, but they work in conjunction when it comes to subjective predictions. People's naïve theories seem to include an overall expectation that positive qualities maximize electoral performances. Therefore, perceived competence, sociability, and pleasantness are anticipated to 
jointly favor the election of a candidate. We did not found any evidence of compensatory effects (Judd et al., 2005) and it is likely that compensation primarily occurs when perceivers compare two targets and they are somehow motivated to see something good in everyone (see Judd et al., 2005, Study 4 and 5). In contrast, in the case of voting decisions the goal is to identify the best possible candidate and people are likely to believe that the candidate who scores higher on all dimensions is indeed the best one. This common sense expectation, however, it is not supported by the analyses of actual elections. Whereas the effects concerning perceived competence are in line with people's intuitions, being perceived as more sociable than one's opponent is not necessarily a desirable feature for a politician. A sociable face can support individual achievement in several life domains, but it appears here to disrupt the chances of winning political contests. 


\section{References}

Abele, A., \& Wojciszke, B. (2007). Agency and communion from the perspective of self versus others. Journal of Personality and Social Psychology, 9, 751-763.

Ballew, C. C., \& Todorov, A. (2007). Predicting political elections from rapid and unreflective face judgments. PNAS, 104, 17948-17953.

Chiao, J. Y., Bowman, N. E., \& Gill, H. (2008). The political gender gap: Gender bias in facial inferences that predict voting behavior. PLoS ONE, 3, e3666.

Cuddy, A. J. C., Fiske, S. T., \& Glick, P. (2008). Warmth and competence as universal dimensions of social perception: The Stereotype Content Model and the BIAS Map. In M. P. Zanna (Ed.), Advances in Experimental Social Psychology (vol. 40, pp. 61-149). New York, NY: Academic Press.

Fiske, S. T., Cuddy, A. J. C., \& Glick, P. (2007). Universal dimensions of social cognition: Warmth and competence. Trends in Cognitive Sciences, 11, 77-83.

Fiske, S. T., Cuddy, A. J. C., Glick, P., \& Xu, J. (2002). A model of (often mixed) stereotype content: Competence and warmth respectively follow from status and competition. Journal of Personality and Social Psychology, 82, 878-902.

Funk, C. L. (1996). The impact of scandal on candidate evaluations: An experimental test of the role of candidate traits. Political Behavior, 18, 1-24.

Funk, C. (1997). Implications of political expertise in candidate trait evaluations. Political Research Quarterly, 50, 675-697.

Judd, C. M., James-Hawkins, L., Yzerbyt, V. Y., \& Kashima, Y. (2005). Fundamental dimensions of social judgment: Understanding the relations between competence and warmth. Journal of Personality and Social Psychology, 89, 899-913. 
Kervyn, N., Judd, C. M., \& Yzerbyt, V. Y. (in press). You want to appear competent? Be mean! You want to appear sociable? Be lazy! Group differentiation and the compensation effect. Journal of Experimental Social Psychology.

Kervyn, N., Yzerbyt, V. Y., Demoulin, S., \& Judd, C. M. (2008). Competence and warmth in context: The compensatory nature of stereotypic views of national groups. European Journal of Social Psychology, 38, 1175-1183.

Kervyn, N., Yzerbyt, V. Y., Judd, C. M., \& Nunes, A. (2009). A question of compensation: The social life of the fundamental dimensions of social perception. Journal of Personality and Social Psychology, 96, 828-842.

Kinder, D. R., \& Sears, D. O. (1985). Public opinion and political action. In G. Lindzey \& E. Aronson, (Eds), Handbook of Social Psychology. New York: Random House.

Leach, C. W., Ellemers, N., \& Barreto, M. (2007). Group virtue: The importance of morality (vs. competence and sociability) in the positive evaluation of in-groups. Journal of Personality and Social Psychology, 93, 234-249.

Little, A. C., Burris, R. P., Jones, B. C., \& Roberts, S. C. (2007). Facial appearance affects voting decisions. Evolution and Human Behavior, 28, 18-27.

Pinheiro, J. C., \& Bates, D. M. (2000). Mixed-effects models in S and S-PLUS. New York: Springer.

Rosenberg, S., Nelson, C., \& Vivekananthan, P. S. (1968). A multidimensional approach to the structure of personality impressions. Journal of Personality and Social Psychology, 9, 283-294.

Rule, N. O., \& Ambady, N. (2008). The face of success: Inferences from chief executive officers' appearance predict company profits. Psychological Science, 19, 109-111.

Todorov, A., Mandisoza, A. N., Gore, A., \& Hall, C. C. (2005). Inferences of competence from faces predict election outcomes. Science, 308, 1623-1626. 
Todorov, A., Said, C. P., Engell, A. D., \& Oosterhof, N. N. (2008). Understanding evaluation of faces on social dimensions. Trends in Cognitive Sciences, 12, 455-460.

Willis, J., \& Todorov, A. (2006). First impressions: Making up your mind after a 100-ms exposure to a face. Psychological Science, 17, 592-598.

Wojciszke, B., Bazinska, R., \& Jaworski, M. (1998). On the dominance of moral categories in impression formation. Personality and Social Psychology Bulletin, 24, 1245-1257.

Yzerbyt, V. Y., Kervyn, N., \& Judd, C. M. (2008). Compensation versus halo: The unique relations between the fundamental dimensions of social judgment. Personality and Social Psychology Bulletin, 34, 1110-1123.

Zebrowitz, L. A., \& Montepare, J. M. (2008). Social psychological face perception: Why appearance matters. Social \& Personality Psychology Compass, 2, 1497-1517. 


\section{Acknowledgements}

The authors wish to thank Joel Cooper and two anonymous reviewers for their helpful comments on this work. 


\section{Footnotes}

1. This is the specific model which was tested in the analyses (see Pinheiro \& Bates, 2000):

$$
\hat{y}_{i j}=\beta_{0}+\sum_{h=1}^{6} \beta_{h} x_{h i j}+\lambda_{j}+\lambda_{i j}
$$

where

- $i=1, \ldots, 58$ (participants), $j \in\{1, \ldots, 20\}$ (pairs), $h=1, \ldots, 6$ (predictors).

- $\beta_{0}+\sum_{h=1}^{6} \beta_{h} x_{h i j}$ is the fixed part of the model.

- $\lambda_{j}$ are the random effects of pairs and $\lambda_{i j}$ are the random effects of participants within pairs.

2. The actual winner of the election was constant for each specific pair of candidates. Obviously, only one candidate within a couple won the election. For this reason, the 20 pairs of candidates were not included in the model:

$$
\hat{y}_{i j}=\beta_{0}+\sum_{h=1}^{6} \beta_{h} x_{h i j}+\lambda_{i}
$$

where

- $i=1, \ldots, 58$ (participants), $j \in\{1, \ldots, 20\}$ (pairs), $h=1, \ldots, 6$ (predictors).

- $\beta_{0}+\sum_{h=1}^{6} \beta_{h} x_{h i j}$ is the fixed part of the model.

- $\lambda_{i}$ are the random effects of participants.

3. Additional analyses were performed to test whether subjective predictions were related to the actual outcome and whether such relation was affected by the perceived competence and sociability of the candidates. No significant effect emerged. This suggests that participants were not particularly good at predicting the actual winner and this is consistent with the finding that perceived sociability affected the two variables in an opposite way.

4. Data about two specific races were not included in the analyses because of a large gap between the two candidates (i.e., $52.6 \%$ and $22.2 \%$ of the votes). 
Table 1

Subjective likelihood of winning
Actual outcome
Margin of victory

or

\section{Fixed effects}

\begin{tabular}{llllllll} 
& value & st. err. & value & st. err. & value & st. err. \\
Competence & $.052^{* * *}$ & .009 & $.021^{*}$ & .010 & $.596^{* *}$ & .221 \\
Sociability & $.027^{* * *}$ & .008 & $-.030^{* * *}$ & .008 & $-.518^{* *}$ & .172 \\
Pleasantness & $.016^{* *}$ & .006 & -.003 & .006 & .037 & .153 \\
Morality & -.001 & .008 & .007 & .008 & .393 & .221 \\
Prototipicality & .007 & .006 & -.011 & .006 & .083 & .134 \\
Age & .003 & .003 & -.003 & .002 & $-.311^{* * *}$ & .045 \\
\hline
\end{tabular}

Random effects

st. dev.

0.126

0.413

Participants

AIC

BIC
743.788

786.592 st. dev.

1.49E-05

821.172

859.779 st. dev.

3.79E-04

3656.981

3694.601

$* p<.05 * * p<.01 * * * p<.001$ 